\title{
The Relationship between Subclinical Asperger's Syndrome and Frontotemporal Lobar Degeneration
}

\author{
Akira Midorikawa $^{a, b}$ Mitsuru Kawamura ${ }^{b}$ \\ ${ }^{a}$ Department of Psychology, Chuo University, and ${ }^{b}$ Department of Neurology, \\ Showa University School of Medicine, Tokyo, Japan
}

\section{Key Words}

Frontotemporal dementia - Asperger's syndrome - Autistic spectrum disorders •

Premorbid characteristics

\begin{abstract}
Background/Aims: The existence of the behavioral variant of frontotemporal dementia (bvFTD), including senile Asperger's syndrome (AS), has been proposed. However, there are no empirical case reports to support the proposal. In this report, we present 3 patients who showed symptoms of bv-FTD and demonstrated signs of autistic spectrum disorder, especially AS. Methods: We evaluated 3 subjects using the diagnostic criteria for bv-FTD, and their caregivers retrospectively provided data to calculate the Autism-Spectrum Quotient, Japanese version [Wakabayashi et al.: Shinrigaku Kenkyu 2004;75:78-84]. We also compared these data with those obtained from 3 individuals with Alzheimer's disease. Results: All 3 patients met the criteria for bv-FTD and had a higher Autism-Spectrum Quotient score than did comparable Alzheimer's disease subjects. Conclusion: It is possible that some senile persons with frontotemporal lobar degeneration-like maladaptive behavior may suffer from subclinical AS.
\end{abstract}

Copyright $\odot 2012$ S. Karger AG, Basel

\section{Introduction}

In 1944, the Austrian pediatrician Hans Asperger described 'autistic psychopathy' [1], a developmental disorder that came to be known as Asperger's syndrome (AS) [2]. AS is characterized by borderline or normal IQ, social isolation or naive and inappropriate social in- 
teractions, intense interest in only one or two subjects, a lifestyle confined to a narrow and repetitive range of interests, limited or inappropriate expression and body language, and poor motor coordination [3]. Although diagnosis of AS has been confined to children or adolescents for many years, it recently became evident that adults can also meet the criteria for AS [4-7]. These findings suggest that AS is a lifelong condition [8]. Thus far, however, no studies have examined elderly persons with AS.

An epidemiological study of school-age children found that the prevalence of suspected and possible AS in the general population was 0.71\% [9]. Additionally, Szatmari et al. [10] estimated that about $50 \%$ of children with AS reach adulthood without having been evaluated, diagnosed, or treated. Therefore, it is plausible that many people with AS are not diagnosed throughout life, including their older years. It is also possible that individuals who have not been diagnosed or treated function well until old age.

The antisocial behavior of some senile persons has been attributed to frontotemporal lobar degeneration (FTLD) or the behavioral variant of frontotemporal dementia (bv-FTD) [11]. For example, Kertesz [12] described several anomalous behaviors, including antisocial actions, demonstrated by patients with bv-FTD. Although the pathological histories of some patients described in his monograph were confirmed, many patients present with antisocial behaviors in daily clinical practice without confirmation of their pathology. Hodges [13] considered that patients who manifested characteristic behaviors over the course of aging suffered from bv-FTD even when their pathological backgrounds were unknown. Hodges and his colleagues $[14,15]$ subsequently noted two subtypes of patients with bv-FTD: a progressive group where the patients experienced an obvious decrease in cognitive functioning over time, and a nonprogressive group where the patients showed very slow or no progression over several years. Additionally, with respect to the nonprogressive group, they stated that 'It seems increasingly unlikely that they have true FTD but rather a phenocopy, which mimics the behavioral symptoms of bv-FTD. A proportion probably have long-standing personality disorders within the Asperger spectrum, which has decompensated in midlife, whereas others may have a neuropsychiatric disorder' [15]. However, no clear evidence of the relationship between bv-FTD and AS has been reported thus far.

Here, we present 3 elderly persons who developed maladaptive behaviors in old age and examine the possibility that they were suffering from FTLD or senile AS.

\section{Subjects (table 1)}

\section{Case 1}

This patient was a 76-year-old man who had been employed as an office worker for more than 40 years after graduating from college. At 70 years of age, he developed a number of abnormal behaviors and memory problems. First, he washed his hands repeatedly over the course of a day, causing his hands to become rough and dry and resulting in a large water bill. Second, he avoided direct contact with doorknobs and habitually touched them with a dirty hand towel. He also carried the dirty hand towel with him almost constantly, using it as a spittoon because he was unable to swallow his own spit. Third, he refused to eat brown food such as stir-fried vegetables or to eat foods with a hard texture such as beans. Therefore, he tended to eat white foods such as rice or tofu and would often expel beans. Fourth, he ate the same food for several weeks. For example, he ate only unadon (a Japanese dish consisting of rice topped with grilled eel) for several weeks and then ate only soba (Japanese buckwheat noodles) for several weeks. Another stereotypical behavior was observed in shopping situations. Every morning, he went shopping at the same department store, bought the same goods, and then visited a soba shop. Although his family com- 
Table 1. Case history of the 3 patients

\begin{tabular}{|c|c|c|c|c|c|}
\hline Subject & Sex & $\begin{array}{l}\text { Age } \\
\text { years }\end{array}$ & $\begin{array}{l}\text { Academic } \\
\text { background }\end{array}$ & Premorbid occupation & Behavioral characteristics after onset \\
\hline Case 1 & Male & 75 & College & Trading company employee & $\begin{array}{l}\text { 'Going-my-way' behavior, stereotyped } \\
\text { behaviors, obsessive-compulsive disorder }\end{array}$ \\
\hline Case 2 & Male & 69 & High school & Corporate employee & Repetitive shoplifting, obsessive gambling \\
\hline Case 3 & Male & 76 & College & $\begin{array}{l}\text { Junior high school mathematics } \\
\text { teacher }\end{array}$ & $\begin{array}{l}\text { Lack of compassion for others, obsessed with } \\
\text { objects }\end{array}$ \\
\hline
\end{tabular}

Table 2. Neuropsychological profile of the 3 patients

\begin{tabular}{|c|c|c|c|c|c|c|c|c|c|c|}
\hline \multirow[t]{2}{*}{ Subject } & \multirow{2}{*}{$\begin{array}{l}\text { MMSE } \\
(/ 30)\end{array}$} & \multirow{2}{*}{$\begin{array}{l}\text { FAB } \\
(/ 18)\end{array}$} & \multicolumn{8}{|c|}{ WAIS-R } \\
\hline & & & IQ & $\begin{array}{l}\text { infor- } \\
\text { mation }\end{array}$ & $\begin{array}{l}\text { picture } \\
\text { completion }\end{array}$ & $\begin{array}{l}\text { similar- } \\
\text { ities }\end{array}$ & $\begin{array}{l}\text { digit } \\
\text { symbol }\end{array}$ & $\begin{array}{l}\text { digit } \\
\text { span }\end{array}$ & $\begin{array}{l}\text { block } \\
\text { design }\end{array}$ & $\begin{array}{l}\text { picture } \\
\text { arrangement }\end{array}$ \\
\hline Case 1 & 22 & 4 & 81 & 11 & 4 & 6 & 7 & & & \\
\hline Case 2 & 24 & 13 & 125 & 13 & 12 & 14 & 15 & 12 & 11 & 13 \\
\hline Case 3 & 28 & 11 & 118 & 12 & 12 & 15 & 12 & 11 & & \\
\hline
\end{tabular}

Table 3. Core diagnostic features of bv-FTD [11] and characteristic symptoms among the 3 patients

\begin{tabular}{|c|c|c|c|c|c|}
\hline \multirow[t]{2}{*}{ Subject } & \multicolumn{5}{|l|}{ Core diagnostic feature } \\
\hline & $\begin{array}{l}\text { insidious onset and } \\
\text { gradual progression }\end{array}$ & $\begin{array}{l}\text { early decline in social } \\
\text { interpersonal conduct }\end{array}$ & $\begin{array}{l}\text { early impairment in } \\
\text { regulation of personal } \\
\text { conduct }\end{array}$ & $\begin{array}{l}\text { early emotional } \\
\text { blunting }\end{array}$ & early loss of insight \\
\hline Case 1 & Gradual progression & Decline in manner & Inertia & Indifference to others & $\begin{array}{l}\text { Unconcern about mental } \\
\text { failure }\end{array}$ \\
\hline Case 2 & Gradual progression & Criminal act & Inertia & Loss of empathy & Denial of symptoms \\
\hline Case 3 & $\begin{array}{l}\text { Gradual onset after } \\
\text { stroke }\end{array}$ & Tactlessness & Inertia & Loss of empathy & $\begin{array}{l}\text { Unconcern about mental } \\
\text { failure }\end{array}$ \\
\hline
\end{tabular}

plained about his memory problems, he continued to use a credit card and to shop alone at a department store. His neuropsychological profile is presented in table 2 . Because he refused to complete some tests, we were unable to collect sufficient information about his cognitive ability. On the Mini-Mental State Examination (MMSE) [16], he showed deficits in mental calculation and visuospatial ability, but his memory function was well preserved. According to the Frontal Assessment Battery (FAB) [17], he was suffering from severe deterioration of frontal functions. His scores on the 'programming' and 'prehension behavior' subscales of the FAB were zero. Magnetic resonance imaging (MRI) showed bilateral frontal lobe atrophy. ${ }^{99 \mathrm{~m}} \mathrm{Tc}$-ethyl cysteinate dimer single-photon emission computed tomography (ECD-SPECT) showed hypoperfusion of the left temporal lobe. This patient showed five core diagnostic features of bv-FTD (table 3) and the following supportive features [11]: (a) decline in personal hygiene and grooming, (b) mental rigidity and inflexibility, (c) dietary change, (d) perseverative and stereotyped behavior, (e) incontinence, (f) neuropsychological impairment on frontal test, and (g) predominant anterior temporal lobe abnormality. 
Case 2

This patient was a 69-year-old man who had been employed as an office worker for more than 40 years after graduation from high school. He retired at the age of 60 years and suffered from depression. Following a short period of treatment, he refused medical care. After retirement, he was employed by another company and organized a new department, where he was responsible for a major loss. Although he seemed to have recovered from his depression after 8 years, he visited the hospital due to several abnormal behaviors. First, he repeatedly shoplifted and was sometimes arrested, and second, he was addicted to horse racing and the lottery and incurred heavy losses. Although he was usually able to remember these episodes, he could not explain their cause. Indeed, he would make excuses for these episodes and even blamed his wife for their occurrence. His MMSE data also showed borderline deterioration (table 2) in that he was disoriented, and his ability to perform mental calculations was impaired. Although his intelligence was intact (estimated IQ of 125), he showed disturbances in his frontal lobe functions (FAB score of 13/18). MRI data showed multiple small infarctions in the right frontal lobe and N-isopropyl-[I-123]p-iodoamphetamine ( ${ }^{123} \mathrm{I}-\mathrm{IMP}$ ) SPECT images showed slight hypoperfusion in the right posterior cortex. This patient showed five core diagnostic features of bv-FTD (table 3) and the following supportive features: (a) mental rigidity and inflexibility, (b) perseverative and stereotyped behavior, and (c) neuropsychological impairment on frontal test.

Case 3

This patient was a 76-year-old former mathematics teacher who had graduated from college. He had suffered a cerebral infarction in the right parietal lobe in 1999. In 2007, his family noticed that his memory was impaired and consulted a psychiatric clinic about a number of problems. First, his son-in-law suffered severe psychological distress due to the patient's inability to pay attention to others. Second, the patient's range of attention narrowed, and he was unable to plan ahead. For example, he was unable to return home from walks because he became distracted and got lost. Multiple infarctions and hypoperfusion in the bilateral frontal lobes and the right temporal lobe were observed 2 years later. His neuropsychological results showed intact intelligence (estimated IQ of 118) and memory functioning (MMSE score of 28/30); however, he also demonstrated frontal lobe dysfunction (FAB score of 11/18). This patient showed five core diagnostic features of bv-FTD (table 3) and the following supportive features: (a) mental rigidity and inflexibility, (b) perseverative and stereotyped behavior, (c) neuropsychological impairment on frontal test, and (d) predominant frontal lobe abnormality.

\section{Results}

Although all patients presented with maladaptive behaviors in late and met core diagnostic features of bv-FTD [11] (table 3), these behaviors were on a continuum with their premorbid traits according to their caregivers. For example, the family of case 1 wondered if he might be suffering from AS during his senile period after they read a newspaper story about the characteristics of this disorder. We conducted semi-structured retrospective interviews based on the Japanese version of the Autism-Spectrum Quotient (AQ) [18] with the patients' caregivers to identify relevant symptoms. This measure, originally developed by Baron-Cohen et al. [19], is a self-administered questionnaire. We used the semi-structured interviews to clarify the patients' premorbid characteristics. In the interview, we defined the premorbid period as the ages when the patients had no apparent maladaptive behaviors. We also administered these instruments to 3 control caregivers whose wives or husbands had been given a 


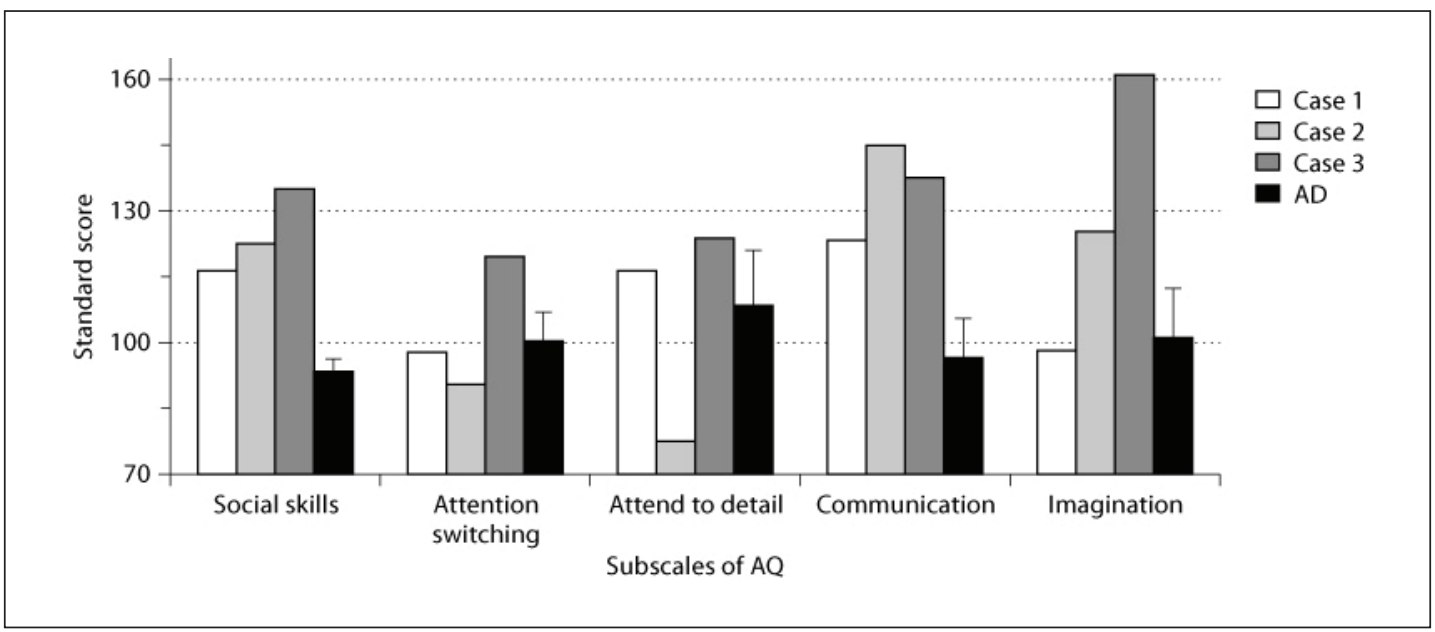

Fig. 1. AQ data for patients with bv-FTD and AD. Each score was standardized based on the scores of the normal population (average of 100, standard deviation of 15). Data were analyzed with t tests, and statistical significance was set at $\mathrm{p}<0.05$.

probable diagnosis of Alzheimer's disease (AD; average age 72.0 years). The AD patients were diagnosed based on NINCDS-ADRDA criteria [20]. All data were standardized according to data from the normal population (mean of 100, standard deviation of 15) and analyzed using $\mathrm{t}$ tests with the statistical significance set at $\mathrm{p}<0.05$.

Our 3 patients had higher AQ scores than did control participants with probable AD (fig. 1). Scores on the 'social skills' $(\mathrm{t}(4)=5.30, \mathrm{p}<0.01)$ and 'communication' $(\mathrm{t}(4)=4.27$, $\mathrm{p}<0.05)$ subscales of the AQ were significantly higher in our 3 patients than in the controls.

\section{Discussion}

This article presents 3 patients with senile-onset degenerative disease. All 3 patients met the criteria for clinical diagnosis of FTD or FTLD [11] or demonstrated characteristics of bvFTD [21]. However, they also showed personality deviations even before the onset of the disease. According to data obtained via semi-structured interviews based on the AQ [19], these patients showed a high probability of suffering from autistic spectrum disorder even before the onset of the disease under examination. Based on these observations, we believe that our patients developed senile AS. This conclusion supports previous reports by Hornberger et al. [15].

Several clinical signs indicated that these 3 patients experienced symptoms associated with AS during premorbid periods. First, family reports that these patients' relationships with their best friends were relatively poor and that they were not very motivated to develop friendships are consistent with descriptions of adolescents with AS [22]. Second, on the five subdomains of the AQ ('social skills', 'attention switching', 'attention to detail', 'communication', and 'imagination'), our patients had high scores for 'communication', the domain in which AS subjects scored significantly higher than control subjects [6].

However, several questions about the diagnostic status of our 3 patients remain. First, why had the diagnosis of AS not been made much earlier? The delay in making this diagnosis may be attributable to the relatively recent introduction of the term 'Asperger's syndrome'. Additionally, this term did not gain popularity until our patients were older. Moreover, au- 
tistic spectrum disorder is not a single distinctive disorder but rather a continuum of disorders [23] so that patients with AS often display a wide range of individual differences. Thus, individuals with severe AS may be detected at young ages, while those with milder impairments may remain undiagnosed and rely on multiple strategies to adapt to their circumstances.

Second, why did our patients demonstrate antisocial behavior when they were elderly? One possible reason is that individuals who suffer from both senility and AS may be exceptionally vulnerable to aging. Retirement may also release them from social constrains. It has been proposed that autism confers additional vulnerability to stress and anxiety [24]; thus, subjects with subclinical AS may also be more vulnerable to the impact of several stressors. Indeed, the cognitive decline associated with aging or illness may be one source of stress. As a result, the behavioral adaptations developed by our patients may have been disrupted, allowing emergence or reinforcement of premorbid characteristics that resemble bv-FTD symptoms.

Our results support the notion that individuals with the nonprogressive type of bv-FTD are unlikely to have true FTD but rather suffer from a phenocopy, and 'A proportion probably have long-standing personality disorders within the Asperger spectrum' [15]. However, our study has several limitations. First, our results were based on a small sample, and the data were not representative. Second, our results were based on retrospective reports, which were likely affected by rater bias. Indeed, the raters may have been more influenced by the patients' present characteristics than by their premorbid characteristics.

Finally, our data imply that premorbid characteristics may provide information that is highly relevant to diagnosing those who subsequently develop dementia.

\section{Acknowledgements}

We thank Prof. M.W. Miller for his advice. This study was supported by the Chuo University Special Research Fund, Tokyo, Japan, and a Grant-in-Aid for Young Scientists (B) (No. 22730587), Ministry of Education, Science and Culture (MEXT) (to A.M.), and by the Tamagawa University Center of Excellence and a Grant-in-Aid for Scientific Research (No. 23591283) under the MEXT (to M.K.).

\section{References}

-1 Asperger H: Die 'autistischen Psychopathen' im Kindesalter. Arch Psychiatr Nervenkrankheiten 1944;117:76-136.

-2 Wing L: Asperger's syndrome: a clinical account. Psychol Med 1981;11:115-129.

-3 Wing L: Autistic spectrum disorders. BMJ 1996;312:327-328.

-4 Roy M, Dillo W, Emrich HM, Ohlmeier MD: Asperger's syndrome in adulthood. Dtsch Arztebl Int 2009;106:59-64.

-5 Ng B, Au M, Verhoeven M, Johnston L, Perkins C: The diagnosis of Asperger's syndrome in an adult presenting with an index episode of mania. Gen Hosp Psychiatry 2003;25:295-297.

-6 Kanai C, Iwanami A, Hashimoto R, Ota H, Tani M, Yamada T, et al: Clinical characterization of adults with Asperger's syndrome assessed by self-report questionnaires based on depression, anxiety, and personality. Res Autism Spectr Disord 2011;5:1451-1458.

-7 Sintes A, Arranz B, Ramirez N, Rueda I, San L: Asperger syndrome: can the disorder be diagnosed in the adult age? Actas Esp Psiquiatr 2011;39:196-200.

-8 Khouzam HR, El-Gabalawi F, Pirwani N, Priest F: Asperger's disorder: a review of its diagnosis and treatment. Compr Psychiatry 2004;45:184-191. 
9 Ehlers S, Gillberg C: The epidemiology of Asperger syndrome. A total population study. J Child Psychol Psychiatry 1993;34:1327-1350.

-10 Szatmari P, Archer L, Fisman S, Streiner DL, Wilson F: Asperger's syndrome and autism: differences in behavior, cognition, and adaptive functioning. J Am Acad Child Adolesc Psychiatry 1995;34:16621671.

-11 Neary D, Snowden JS, Gustafson L, Passant U, Stuss D, Black S, et al: Frontotemporal lobar degeneration: a consensus on clinical diagnostic criteria. Neurology 1998;51:1546-1554.

12 Kertesz A: The Banana Lady and Other Stories of Curious Behavior and Speech. Victoria Trafford Publishing, 2006.

13 Hodges JR: Frontotemporal Dementia Syndromes. Cambridge, Cambridge University Press, 2007.

14 Hodges JR: Afternoon Workshop 3: New Directions in the Assessment of Frontotemporal Dementia. INS/ASSBI 4th Pacific Rim Conference, Auckland, 2011.

-15 Hornberger M, Piguet O, Kipps C, Hodges JR: Executive function in progressive and nonprogressive behavioral variant frontotemporal dementia. Neurology 2008;71:1481-1488.

16 Folstein MF, Folstein SE, McHugh PR: 'Mini-mental state'. A practical method for grading the cognitive state of patients for the clinician. J Psychiatr Res 1975;12:189-198.

-17 Dubois B, Slachevsky A, Litvan I, Pillon B: The FAB: a Frontal Assessment Battery at bedside. Neurology 2000;55:1621-1626.

- 18 Wakabayashi A, Tojo Y, Baron-Cohen S, Wheelwright S: The Autism-Spectrum Quotient (AQ) Japanese version: evidence from high-functioning clinical group and normal adults (in Japanese). Shinrigaku Kenkyu 2004;75:78-84.

19 Baron-Cohen S, Wheelwright S, Skinner R, Martin J, Clubley E: The autism-spectrum quotient (AQ): evidence from Asperger syndrome/high-functioning autism, males and females, scientists and mathematicians. J Autism Dev Disord 2001;31:5-17.

20 McKhann G, Drachman D, Folstein M, Katzman R, Price D, Stadlan EM: Clinical diagnosis of Alzheimer's disease: report of the NINCDS-ADRDA Work Group under the auspices of Department of Health and Human Services Task Force on Alzheimer's Disease. Neurology 1984;34:939-944.

-21 Knibb JA, Kipps CM, Hodges JR: Frontotemporal dementia. Curr Opin Neurol 2006;19:565-571.

-22 Whitehouse AJ, Durkin K, Jaquet E, Ziatas K: Friendship, loneliness and depression in adolescents with Asperger's Syndrome. J Adolesc 2009;32:309-322.

-23 Wing L, Gould J: Severe impairments of social interaction and associated abnormalities in children: epidemiology and classification. J Autism Dev Disord 1979;9:11-29.

24 Groden J, Cautela J, Prince S, Berryman J: The impact of stress and anxiety on individuals with autism and developmental disabilities; in Schopler E, Mesibov GB (eds): Behavioral Issues in Autism. New York, Plenum Press, 1994, pp 177-194. 